\title{
Bridging Rhetorical Genre Studies and Ethics of Representation in Meeting Minutes
}

\author{
Kelly Whitney* \\ January 4, $2019^{\dagger}$
}

\begin{abstract}
This essay describes a project that introduces undergraduate students in a technical and professional writing course to rhetorical genre studies, context, and ethics. In this project, students (1) study examples of meeting minutes and consider their functions within specific contexts, (2) take meeting minutes of a class session, and (3) analyze their minutes to abstract larger lessons on the rhetorical, epistemological, and ethical work of technical and professional writing. This project brings students' attention to the complex decision-making processes writers face as they seek to produce useful, ethical, recognizable professional documents.
\end{abstract}

\section{Introduction}

Meeting minutes are one of the most common types of professional writing. Governments, academic committees, private organizations, businesses, and even student clubs document the topics of a meeting, including decisions that were made, in minutes. Additionally, minute takers often record assigned tasks and their due dates as a way to hold others accountable for their work (Heathfield, 2017; Wolfe, 2006). Despite the common practice and benefits of taking minutes, technical and professional writing textbooks give inadequate attention to meeting minutes (Ingham, 2008; Wolfe, 2006). Indeed, in my own technical and professional writing courses, I have found the majority of students have never heard of meeting minutes, and few have experience taking minutes. When meeting minutes are mentioned in textbooks, they are, like many forms of professional and technical writing, treated as neutral documents that capture an objective reality and represent that reality in writing. Such representations of professional and technical

\footnotetext{
*Department of English, The Ohio State University at Mansfield, whitney.69@osu.edu. Copyright 2019 Kelly Whitney. This work is licensed under a Creative Commons Attribution-NonCommercial 4.0 International License (http://creativecommons.org/licenses/by-nc/4.0/).

${ }^{\dagger}$ Submitted, 7/25/2017; Accepted, 11/6/2018.
} 
writing - writing as true, neutral, and objective - deflect attention away from writers' decision-making processes and the ethical implications of their decisions (Dombrowski, 2000; Ornatowski, 1992). In this article, I describe an assignment that invites students to practice taking meeting minutes by recording a specific class session and then to analyze the effectiveness and effects of the minutes.

This project was assigned to students in a professional and technical writing course, which is the second of a vertical two-course general education writing program. Because this course fulfills a general education writing requirement, students from any discipline can enroll as long as they have passed the first-year writing course or its equivalent. Consequently, any given section of this course can have students in professional and technical fields as well as those from the arts and humanities. Additionally, students may or may not have taken courses in their majors upon enrolling in this course.

To accommodate such a variety of students, I structure this course as an introduction to professional and technical writing for academic, professional, and civic purposes. The course is divided into six units with each unit focusing on a specific topic and deliverable. In the first half of each unit, students study a specific topic (e.g., accessibility and (dis)abilities) by reading and discussing texts that address the unit's topic. In the second half of the unit, students apply these lessons by composing professional and technical texts (e.g., a usability report).

For the meeting minutes assignment, the larger lessons center on rhetorical genre studies, context, and ethics of representation, which I discuss further in the following sections, and the deliverables are the minutes themselves and a memo wherein students analyze their minutes. However, this assignment departs from the course structure in that it is not located in a specific unit but spans the entire semester. During the second week of the semester, students sign up for a day to serve as class "secretary," and on their designated day, students take minutes of the class session and upload their minutes to our learning management system, Canvas. To complete this project, in a professional memo written to me, students analyze their minutes in light of the larger lessons (rhetorical genre studies, context, and ethics of representation) that frame the assignment. Therefore, I receive students' minutes and memos on a rolling basis throughout the semester.

\section{Rhetorical Genre Studies and Context}

One objective of this assignment is for students to learn about and practice negotiating the complex relationships between genre and context. This negotiation requires students to see genre as more than a system of classification but as a discourse that acts within (and calls into being) rhetorical situations, a perspective that Miller (1984) offers in her landmark essay "Genre as Social Action." In other words, genre is a social discourse that mediates knowledge and action within particular communities, including those in professional and technical spaces (Bawarshi \& Reiff, 2010; Miller \& Kelly, 2017; Moeller \& Christensen, 2009; Spinuzzi, Hart-Davidson, \& Zachry, 2006). Recognizing that genres 
and context are inextricably linked, scholarship in technical and professional writing pedagogy seeks to shift the purposes and scope of the writing class away from teaching students how to write and towards studying how texts emerge and circulate in particular contexts (Bawarshi \& Reiff, 2010; Dias \& Paré, 2000; Dias, Freedman, Medway, \& Paré, 1999; Freedman \& Adam, 1996; Paré, 2002). This approach reflects the idea that writing is based on community-specific situations. To be able to navigate various writing situations, then, students must learn rhetorical flexibility: they learn how to identify rhetorical situations and generic conventions and then make writing decisions accordingly.

To illustrate the relationships between genre and context, I invite students to examine examples of meeting minutes from different contexts (Part I of the assignment). The examples I provide are based on students' professional and academic interests and have included minutes from meetings held by the Centers for Disease Control and Prevention (CDC) and a local school board, both of which I found online. I have also used minutes from a community sports clubs that I was once a member of and whose emails and meeting minutes I still receive. As a class, we discuss our observations of each document, including the style and format of the writing (e.g., formality, use of sentences or bullet points) and the scope of information represented, and we consider what these features suggest about the context of each document. For instance, students recognize that the formality and extensive detail of the CDC's minutes reflect the serious work the organization performs and provide transparency to the public. Similarly, the minutes taken by the community sports club includes jargon, which students attribute to audience: they suspect that other club members are those who will use this document, which, they claim, justifies the use of jargon. We also consider the scope of each document, paying particular attention to the types of information included and excluded in different meeting minutes. The community sports club minutes include the specific ideas that were discussed and debated preceding a vote whereas the local school board's minutes document only the vote or decision that was made and not the process it took to get there. Again, we turn to context to make sense of these generic discrepancies. Students recognize that an organization such as a local sports club might have a high turnover of leaders; therefore, the secretary is perhaps imagining a future user (i.e., future leadership) who could return to the document to see the factors that led to the decision. As these few examples suggest, through an in-class genre analysis, we articulate the connections between genre and context, showing that genres are not static, prescriptive, formulaic forms of writing but rather take the shape of their specific context.

Bearing in mind the relationship between genre and context, on their designated days as secretary, students negotiate the meeting minutes genre and their context in order to determine what to document and how to document it in their minutes. That is, I don't give students a set format for minutes; instead, each student decides for themself how to capture the class session in a way that is most effective for users (fellow classmates) of the document. In professional and technical communications, effective writing means useful writing, or writing that is actionable for their intended users (Wolfe, 2010). Of course, what counts as useful depends on context. In her rhetorical genre analysis of meeting 
minutes, Wolfe (2006) evaluates the usefulness (or lack thereof) of minutes in various contexts. As she describes, transcript style minutes capture the meeting verbatim but lack a clear purpose; action-oriented minutes emphasize tasks and action items and are "the norm for project teams in most workplace settings" (p. 355); and parliamentary style minutes prioritize individual actions and votes and are most common in governmental and academic settings. In a follow-up rationale memo to his minutes (Part III of the assignment), one student accounts for his decision to summarize a class discussion in lieu of transcribing it. He writes:

As I was creating these minutes, the audience and function I had in mind were absentees who needed to know what they missed and people who were present that wanted a refresher on what happened during class. I believe that noting summaries of the discussions is enough to fill this purpose. Had I included transcriptions of what everyone said during class, the purpose, function, or audience of the minutes would not change, but its usability would take a hit.

As this student recognizes, to compose useful minutes, writers make significant editorial decisions in order to capture the messiness of spoken discourse in written form (Ingham, 2008). Indeed, this is what makes the meeting minutes assignment challenging: the secretary negotiates their rhetorical context, imagines what will make the document most useful, and makes decisions accordingly. Additionally, the writer works within generic constraints to ensure the minutes are recognizable as minutes and perform the genre's functions. Because of the numerous decisions the secretary must make, a seemingly banal form of writing such as meeting minutes, to be useful, requires significant rhetorical awareness and negotiation of context and genre.

\section{Ethics and/of Representation}

As discussed above, the meeting minutes assignment offers students an opportunity to practice negotiating context and genre in order to produce a useful deliverable. Still, writing scholars have raised concerns that focusing on context or usefulness of writing risks neglecting ethics (Ornatowski, 1992). In fact, the first principle listed in the Association of Teachers of Technical Writing's (n.d.) code of ethics for students is "To foster a sense of ethical responsibility to themselves, stakeholders, and the public." Hausman (2000) has also called for technical and professional communication pedagogy to address the ethical and cultural effects of students' writing. She writes, "Students in technical writing courses... need to see their own writing as participating in the cultural context in which they live - not only in terms of influences on their writing, but the ways in which their work contributes to or even just represents that cultural context" (p. 274). In what follows, I discuss how the meeting minutes assignment bridges the gap between genre, context, and ethics and makes space for students to analyze the ethical functions of professional and technical writing vis-à-vis their meeting minutes. 
One key ethical function of professional and technical writing this project surfaces is the role of power in shaping users' and audiences' knowledges. For the purposes of this assignment, I invite students to consider power in two (related) ways: the authority that is often granted to professional and technical writing and, consequently, the influence that professional and technical writers have in constructing and circulating knowledge (see also McEachern, 1998). Professional and technical writing are often portrayed as neutral, objective forms of writing that dispense truth, and articulating professional and technical writing in such a way deflects attention to the ways knowledge is contingent upon the community in which it circulates (Miller, 1979). Therefore, during our in-class genre analysis (Part I), I ask pointed questions that direct students' attention to the ways they may be more easily persuaded by professional and technical texts because of the perception that these forms of writing are neutral, true, and objective. Through this discussion, students come to see how these features enable professional and technical writing to authorize what counts as knowledge. The goal of this discussion is not to persuade students to reject knowledge that circulates in professional and technical writing but to help them recognize the epistemological and ethical work that such texts, and the writers of such texts, perform.

In light of the influence professional and technical genres have in shaping users' and audiences' knowledge, writers have a responsibility to account for the ethical, cultural, epistemological effects of their writing. In the critical reflection (Part III of the assignment), therefore, students work through their decision-making processes and account for the epistemological work of their writing, paying particular attention to the effects of their writing on users' knowledge. In her follow-up analysis of her minutes, one student recognizes the power she wields as minute-taker: "[By deciding what to include and what not to include] I was the one determining which topics we talked about in class actually contributed to our learning objectives for the day.... This is important to consider because what I choose to include could change how the audience interprets the minutes and what happened in class that day." This student recognizes that because of the authority granted to the meeting minutes genre, she, the writer of the minutes, determined her readers' understanding of the class session. By tracing the relationships between power and knowledge, even within the constraints of one particular genre, students begin to denaturalize professional and technical writing as true, objective, and neutral. Instead, students see how professional and technical writing does things and how their writing has effects in the world, even if this power is limited to shaping classmates' perceptions of what happened in class on a particular day.

Another way this project bridges the gap between rhetorical genre studies, context, and ethics is by surfacing what Stephen Katz (1992) calls the ethics of expediency, or writing that privileges its message over, or even at the expense of, ethical matters. In this case, ethics of expediency calls attention to writing that focuses on generic conventions at the expense of ethical, cultural effects that writing conveys. For instance, in the example minutes we study in class (Part I), students recognize that some minutes identify individual speakers while other minutes make no mention of individual contributors. We 
discuss the ethical effects of this decision: On one hand, omitting names allows readers to consume meeting minutes more quickly and emphasizes ideas and action items. On the other hand, adding names recognizes individual contributions and labor, echoing the feminist practice of amplification (see Eilperin, 2016). Even the language used in this assignment, especially the term "secretary," invites critical discussions on the ethics of expediency. By weighing these options, students recognize that such decisions have both ethical and hermeneutical effects for the user.

\section{Final Thoughts on the Assignment}

What I like most about this assignment is that it allows - even requires - students to "play" with their writing and experiment with new formats and styles. In their follow-up memos, students often discuss the freedom they have in taking minutes as both a blessing and a burden. On one hand, they enjoy being able to make their own decisions on what to document and how to document it based on the specific class session. On the other hand, they recognize that making these decisions adds to the complexity of writing. Of course, writing is a series of making rhetorically informed decisions, and asking students to make and justify these decisions - and analyze the effects of these decisions - is a necessary part of getting them to see themselves as agented writers whose work does things in the world. Still, like any writing assignment, students will benefit from explicit instruction on how the meeting minutes assignment can transfer to other writing situations. Therefore, I regularly remind students that what they are learning is not necessarily how to write meeting minutes by following a prescriptive format but through negotiating context and genre in order to compose effective, ethical documents. That way, when students come across an instance when they need to take meeting minutes in the future, they have the conceptual framework and rhetorical flexibility to appropriate generic conventions to compose useful, ethical minutes.

This assignment has offered a few unexpected benefits for my own teaching. Because the secretary makes meeting minutes available to the class within 24 hours of the recorded session, students who missed class or who have questions can first turn to the minutes for answers. This has made my email exchanges with students more productive since students can point to a specific topic from the minutes and ask more pointed questions (and has altogether eliminated the "What did I miss in class?" emails). A second benefit is that I can use students' minutes as another form of assessment by comparing my goals and objectives of a particular session with what made it in the minutes. For instance, after a particularly intense discussion or activity, I can look at the minutes to see how the secretary captured (or not) its key purpose, lesson, or outcome, identify gaps or inconsistencies, and plan accordingly for the following class. I share with students how I use their minutes in my lesson planning in this way, which serves as another reminder for them to attend to the usefulness and effects of their professional and technical writing.

The three components of this assignment - studying the meeting minutes genre, taking minutes, and analyzing the minutes - offer students the opportunity to study, practice, and 
analyze a common form of professional and technical writing. Students gain experience working within the flexibilities and rigidities of a particular genre to be taken up in a specific context while also accounting for the ethical work of their writing. Because introductory writing courses play a significant part in shaping how students write, writing instructors have an opportunity to frame writing as an ethical practice. Relatedly, as this activity demonstrates, discussions on genre can (or should) also include the ethical and cultural effects genres enact. Disciplining students to approach writing as an ethical performance, then, prepares students to approach other academic, professional, and civic writing situations with the same ethical imperative.

\section{Assignment-Class Secretary/Meeting Minutes Analysis}

See the Supplementary Files for this article at thepromptjournal.com for a PDF facsimile of the original formatting of this assignment.

\section{Overview and Purpose}

This assignment asks you to study, practice, and analyze a common form of professional writing: meeting minutes. Meeting minutes are "the written or recorded documentation that is used to inform attendees and non-attendees what was discussed and what happened during a meeting" (Heathfield, 2017). While not particularly difficult, taking minutes requires the minute-taker (secretary) to make decisions on how the meeting is represented to audiences. In fact, because of the many potential audiences and purposes of meeting minutes, David Ingham (2008) claims that meeting minutes "represent one of the most complex rhetorical situations imaginable" (p. 229). As such, this activity invites us to [1] study the conventions of the meeting minutes genre and determine how we can work within a genre's flexibilities and rigidities for our own purposes, [2] practice taking meeting minutes, a common form of professional writing, and [3] analyze how the decisions we make in our writing shape our readers' perceptions and knowledge.

\section{Part I: Study the Meeting Minutes Genre}

As a class, we'll study examples of meeting minutes in order to more fully grasp the genre's purposes, conventions, flexibilities, and rigidities. We'll also discuss relationships between these examples and the contexts in which they circulate, and then brainstorm ways we might adapt the genre so it supports our particular context. 


\section{Part II: Take Meeting Minutes}

On your designated days as class secretary, you'll take minutes of the class session. As you take minutes, consider the multiple possible audiences of the minutes (e.g., present classmates and absent classmates) and the multiple possible purposes of the minutes (e.g., to document class discussions, record verbal assignment instructions, serve as a reference point for classmates both present and absent). Keep these multiple audiences and purposes in mind as you decide what to include in your minutes and how to include it, as these decisions will be important to note in part III. Rather than providing you with a specific structure for the minutes, you will determine the format of the document. Refer to the examples we studied to help you decide what to write and how to write it. Save your minutes as a PDF. The file name of the PDF should reflect the date of the minutes (02.12.18.pdf, for example). Within $\mathbf{2 4}$ hours of the class meeting, please upload your PDF to the Canvas discussion "Meeting Minutes."

\section{Part III: Analyze Your Minutes}

Recall Ingham's claim on meeting minutes' complex rhetorical situations (see above). Based on your experience taking minutes, how do you respond to Ingham's statement? To support your claim, review Ingham's article and discuss how you decided what to include (content) and how you included it (style, word choice, format, etc.).

Other questions to consider in your analysis:

- How do these minutes capture a particular narrative of the class session?

- How "True" or "true" are these minutes? That is, what do they not capture, and how would including other points in the minutes change the narrative, function, purpose, and/or audience of the minutes? Consider differences between truth and accuracy.

- What claim(s) might you abstract from this experience about professional/technical communication, genre, and/or meeting minutes?

- What else would you like to discuss about this experience?

Submit your analysis in a professional memo written to me. Also, for a thorough, well-supported, and detailed response, I imagine you'll need the equivalent of at least 1 full page single-spaced. Email me your memo and a copy of your minutes as a single attachment within one week of the class session you recorded. 


\section{References}

Association of Teachers of Technical Writing. (n.d.). Code of ethics. Association of Teachers of Technical Writing.

Bawarshi, A. S., \& Reiff, M. J. (2010). An introduction to history, theory, research, and pedagogy. West Lafayette, IN: Parlor Press.

Dias, P., \& Paré, A. (Eds.). (2000). Transitions: Writing in academic and workplace settings. Cresskill, NJ: Hampton Press.

Dias, P., Freedman, A., Medway, P., \& Paré, A. (1999). Worlds apart: Acting and writing in academic and workplace contexts. Mahwah, NJ: Lawrence Erlbaum.

Dombrowski, P. (2000). Ethics in technical communication. Boston, MA: Allyn \& Bacon.

Eilperin, J. (2016, September). White House women want to be in the room where it happens. The Washington Post.

Freedman, A., \& Adam, C. (1996). Learning to write professionally: "Situated Learning" and the transition from university to professional discourse. Journal of Business and Technical Communication, 10(4), 395-427.

Hausman, B. L. (2000). Rational management: Medical authority and ideological conflict in Ruth Lawrence's breastfeeding: A guide for the medical profession. Technical Communication Quarterly, 9(3), 271-289.

Heathfield, S. M. (2017, July). What are meeting minutes and who records them at a meeting? The Balance Careers.

Ingham, D. (2008). These minutes took 22 hours: The rhetorical situation of the meeting minute-taker. In J. MacLennan (Ed.), Readings for technical communication (pp. 229-231). Ontario: Oxford University Press.

Katz, S. B. (1992). The ethic of expediency: Classical rhetoric, technology, and the Holocaust. College English, 54(3), 255-275.

McEachern, R. W. (1998). Meeting minutes as symbolic action. Journal of Business and Technical Communication, 12(2), 198-216.

Miller, C. R. (1979). A humanistic rationale for technical writing. College English, 40(6), 610-617.

Miller, C. R. (1984). Genre as social action. Quarterly Journal of Speech, 70(2), 151-167.

Miller, C. R., \& Kelly, A. R. (Eds.). (2017). Emerging genres in new media environments. Cham, Switzerland: Palgrave Macmillan.

Moeller, R. M., \& Christensen, D. M. (2009). System mapping: A genre field analysis 
of the National Science Foundation's grant proposal and funding process. Technical Communication Quarterly, 19(1), 69-89.

Ornatowski, C. M. (1992). Between efficiency and politics rhetoric and ethics in technical writing. Technical Communication Quarterly, 1(1), 91-103.

Paré, A. (2002). Keeping writing in its place: A participatory action approach to workplace communication. In B. Mirel \& R. Spilka (Eds.), Reshaping technical communication: New directions and challenges for the 21st century (pp. 57-73). Mahwah, NJ: Lawrence Erlbaum Associates.

Spinuzzi, C., Hart-Davidson, W., \& Zachry, M. (2006). Chains and ecologies: Methodological notes toward a communicative-mediational model of technologically mediated writing. In Proceedings of the 24th annual ACM international conference on Design of communication (pp. 43-50). New York: ACM.

Wolfe, J. (2006). Meeting minutes as a rhetorical genre: Discrepancies between professional writing textbooks and workplace practice tutorial. IEEE Transactions on Professional Communication, 49(4), 354-364.

Wolfe, J. (2010). Team writing: A guide to working in groups. New York, NY: Bedford/St. Martin's. 